\title{
Cognitive Styles and Psychological Resilience as Predictors of Academic Burnout
}

\author{
AbolghasemYaghoobi $^{\text {* }}$, Mehri Mokhtaran ${ }^{2}$, Serwa Mohammadzadeh $^{3}$ \\ 1. Associate professor of Bu Ali Sina University, Hamadan, Iran \\ 2. M.A in Educational psychology, Islamic Azad University, Hamadan Branch, Hamadan, Iran \\ 3. Ph.D. in psychology, Bu Ali Sina University, Hamadan, Iran \\ *Corresponding author Email: yaghobi41@yahoo.com
}

\begin{abstract}
The purpose of this research was to anticipate academic burnout based on cognitive styles and psychological resilience. The statistical population comprised of all the high school girl students in Hamadan, in 2014. The number of society was 9900 students and 368 students selected as sample group according to Morgan's table and by Multistage cluster sampling, students filled3 scales Berso educational fatigue scale, Connor and Davidson resilience scale and latent difficulties group scale. Results showed that there was a significant difference between students 'educational fatigue scale based on cognitive styles and psychological resilience. Cognitive style and psychological resilience also had a significant effect on educational fatigue in students. Totally, psychological variables such as cognitive styles and resilience have an important role in academic performance. With recognizing this determinant and on time intervention, we can decrease and prevent academic burnout.
\end{abstract}

Keywords: educational fatigue, cognitive styles, psychological resilience.

\section{Introduction}

In recent years, educational psychologists researched on factors which are affecting students' educational performance. There are many factors that affect students' educational performance, such as personal factor: psychological hardiness, resilience and cognitive factors including thinking styles, and cognitive styles (Ainley, Graetz, Long, \& Batten, 1995). One of the psychological factors which have an effect on educational performance is academic burnout (Lee \& Ashforth, 1996). Burnout is often described as a syndrome of depersonalization, emotional exhaustion, and reduced personal accomplishment (Maslach, Schaufeli, \& Leiter, 2001). Maslach, Jackson and Leiter (1996) identified emotional exhaustion as the key aspect of burnout whereas Malakh-Pines, Aronson and Kafry (1981) include physical exhaustion characterized by low energy and chronic fatigue. Emotional exhaustion, which refers to feelings of being depleted of one's emotional resources, is regarded as the basic individual stress component of the syndrome. Depersonalization, referring to cynical, negative, or excessively detached responses to other people at work, represents the interpersonal component of burnout. Finally, reduced personal accomplishment refers to feelings of decline in one's competence and productivity, and to one's lowered sense of efficacy, representing the self-evaluation component of burnout (Maslach, 1998) .

Burnout is determined as the major mismatch between the nature of the job and the nature of the person who does the job. The major factors of burnout include work overload, lack of control, lack of reward, lack of community, value conflict, and lack of fairness, which are obvious indications that the person and the job are mismatched (Maslach \& Pines, 1977).

Burnout may lead to mental distress in the form of anxiety, depression, frustration, hostility or fear. Prior research has shown that burnout can lead to lower commitment, higher turnover, 
absenteeism, reduced productivity, low morale, and lower human consideration (Cordes \& Dougherty, 1993).

In recent years, the number of studies about burnout has increased spectacularly and the study of burnout has been extended to almost every job, and even to non- occupational samples, for example, students (Yang, 2004).

Yang (2004) defines student burnout thus: "students in the learning process, because of course stress, course load or other psychological factors, display a state of emotional exhaustion, a tendency to depersonalization, and a feeling of low personal accomplishment." Although, formally speaking, students are neither employed nor do they hold jobs, from a psychological perspective their core activities can be considered "work". Thus, they are engaged in structured, coercive activities (e.g. attending classes, completing assignments) that are directed towards a specific goal (i.e. passing exams). Hence, being a work-related phenomenon, burnout may also exist in students, where it manifests itself by feeling exhausted because of study demands, having a cynical and detached attitude towards one's study, and feeling incompetent as a student (see also (McCarthy, Pretty, \& Catano, 1990; Meier \& Schmeck, 1985). In a similar vein, several studies on stress in academic life have considered students as a kind of employee as well (Chambel \& Curral, 2005). Malakh-Pines et al. (1981) examined and compared burnout in nurses, counselors, educators, and undergraduate students and found that students ranked in the middle to upper levels of the burnout scale. This indicates that students have some degree of burnout during their school learning period. Based on prior research, the syndrome of student burnout is similar to that of service employees. Student burnout can lead to higher absenteeism, lower motivation to do required course work, higher percentage dropout and so on (Meier \& Schmeck, 1985; Ramist, 1981). There are a number of researches in the area of work-related burnout, especially on teacher burnout, burnout among nurses, doctors, managers etc. but very few studies were done on the academic burnout of students.

Cognitive style is another factor which affects the situation of the education. Witkin et al. (1977) brought up cognitive style for the first time. Cognitive style is a style in which data are acquired and processed. Riding \& Smith in 1997 defined the cognitive style as a "stable individual approach" to organize and process the data during learning period and also cognitive style generally is a method in which learner processes data (Dobson, 2009).

One of the traits of cognitive style is its bipolar dimension or components and just like abilities to a great extent is acquired by interactions existing between an individual and the ambient and it can be extended and modified. Therefore, cognitive styles are not stable but are fluent (Sternberg \& Grigorenko, 1997). Tracey and Robbins (2006) found in their study that educational success depends upon cognitive and psychological dimension. Davidson (1977) discovered that there is a relationship between cognitive styles and academic situation of the students. Draper, Stutes, Maples, and Velligan (2009) showed that cognitive styles were formed or established by systematic mental behaviors and here he begins to consider the mental scheme and presenting solutions to the problems and he believes that learning and performance will be affected.

Psychological resilience is defined as an individual's ability to properly adapt to stress and adversity. Individuals show resilience when they can face difficult experiences and rise above them with ease. Resilience is not a scarce ability; in reality, it is seen in the average individual and it can be acquired and developed by virtually anyone. Resilience is more a process, rather than traits (Rutter, 2008). There is a common misconception that people who are the resilient experience no negative emotions or thoughts and display optimism in all situations. Contrary to 
this misconception, the reality remains that resiliency is demonstrated within individuals who can effectively and relatively easily navigate their way around crises and utilize effective methods of coping (Klohnen, 1996). In other words, people who shows the act of resilience are people concluded to have positive emotionality; they are keen to effectively balance negative emotions with positive ones.

Resiliency implies strength, flexibility, a capacity for mastery, and resumption of normal functioning after excessive stress that challenges individual coping skills. Resilient characteristics (self-esteem, hope, and spirituality) have a significant negative relationship with the usage of maladaptive coping strategies (Folkman, Lazarus, Gruen, \& DeLongis, 1986; Richardson, 2002), while academic burnout is a serious problem in education; adolescent students experience a new stress in the society, since students in mental ability, method of learning, style and speed of learning, interest, and motivation for acquiring knowledge and also for academic activities are different from one another; Considering these differences in students and attaching importance upon this phenomenon will help them in learning achievement and improvement of the academic quality. It is noticeable that academic burnout cannot be ignored.

So the main outline of this article is predicting academic burnout based on cognitive styles and psychological resilience.

\section{Material and Methods}

Subjects

Statistical society is containing all female students, at high school level in Hamadan in 2014. Society volume was 9900 students, 368 cases selected by multi-stage cluster sampling and tested.

\section{Measuring tool}

Berso academic Burnout Questionnaire: The questionnaire of academic burn out, developed by Bresó, Salanova, and Schaufeli (2007), evaluates three areas of burn out, i.e. academic fatigue, academic reluctant and inefficiency. The mentioned questionnaire has been ranked with a five-points Likert Scale from strongly agree to strongly disagree. Academic fatigue, academic reluctant and inefficiency include 5 (boring material), 4 (I feel I am not interested in material ), and 6 (I feel I am not able to deal with my material) items, respectively. Bresó et al. (2007) calculated the reliability of .70, .82, and .75 for the three areas of academic burn out.

Connor and Davidson Resilience scale: The scale includes 25 items and measures the strength to cope with pressure and threats that answered by subjects. A five-points Likert-type (no, low, medium, high and very high) to zero (never) to four (very high) is used in grading. Resilience minimum score on this scale is zero and a maximum score is100. Subjects High score in this scale, reflects more resiliency (Connor \& Davidson, 2003).

Group Embedded Figures Test (GEFT) was innovated by Herman Witkin; contains 3 subscales. Section 1 includes 7 pictures and are presented for practice. In this section, the subjects have 2 minutes time to practice. Second and third sections, each contains 9 pictures and to respond to each one, the allocated time will be 5 minutes. In fact, the test grade will be acquired from these two sections. "0" will show perfect correlation and "18" means perfect independence. Each correct response will get "1"grad (Witkin et al., 1977). 


\section{Results}

There are means and standard deviations and Pearson Correlation coefficient between students' academic burnout and its subscales, Cognitive styles, Psychological resilience in tables 1and2.

Table 1. Mean and standard deviation of students' academic burnout Cognitive style, Psychological resilience scores

\begin{tabular}{|c|c|c|c|}
\hline \multirow{3}{*}{ A.B } & Variables & Mean & S.D \\
\cline { 2 - 4 } & Whole Academic burnout score & 48.83 & 9.04 \\
\cline { 2 - 4 } & A.P & 15.98 & 2.62 \\
\cline { 2 - 4 } & A.I & 23.07 & 3.69 \\
\hline E.E & 18.37 & 2.87 \\
\hline \multicolumn{2}{|c|}{ Cognitive style } & 9.54 & 3.50 \\
\hline
\end{tabular}

Table 2. Pearson Correlation coefficient for investigating connection between cognitive styles, resilience and subscales of academic burnout

\begin{tabular}{|c|c|c|c|c|}
\hline \multirow{2}{*}{ variable } & \multicolumn{4}{|c|}{ Academic burnout } \\
\cline { 2 - 5 } & Academic inefficacy & emotional exhaustion & $\begin{array}{c}\text { Academic } \\
\text { pessimism }\end{array}$ & whole academic burnout \\
\hline Cognitive styles & $*_{*}^{*}-0.319$ & $*_{-}-0.317$ & -0.171 & $* *_{-}-0.39$ \\
\hline Resilience & $*_{-}-0.227$ & $* *_{-} 0.358$ & $-0.198 *$ & $* *_{-} 0.365$ \\
\hline
\end{tabular}

$* * \mathrm{P}<0.01$

$* \mathrm{P}<0.05$

As seen in table 2, Pearson coefficient correlations show a significant negative relationship between cognitive styles and the whole academic burnout. It can be said that with an increase in the students' scores in cognitive styles the academic burnout decreases, in other words, the more field independent cognitive styles leads to the less academic burnout in the students, and vice versa, the more field dependent the cognitive styles leads to more academic burnout. The results in table 2 show that there was a significant negative relationship between cognitive styles with academic inefficiency and emotional exhaustion $(\mathrm{p}<0.05)$, therefore, the more field independent students' cognitive styles (higher scores in cognitive styles) leads to less academic inefficiency and emotional exhaustion and vice versa. But there exist not a significant relationship between cognitive styles and academic pessimism ( $\mathrm{p}>0.05)$. Also, Table 2 shows that there is a significant negative relationship (approx. -0.37), between resilience and the whole academic burnout $(\mathrm{r}=0.365, \mathrm{p}<0.01)$. Therefore, we can say that when resilience scores increase, academic burnout rate decreases. Also, there is a significant negative relationship between resilience, with academic inefficiency, emotional exhaustion and academic pessimism $(p<0.05)$, therefore we can say when resilience score increase, academic inefficiency, emotional exhaustion, and academic pessimism decreases. Consequently, the relationship between variable predictors with criterion variable will be confirmed.

Table 3. Summary Results of multivariate regression analysis, the method of entry

\begin{tabular}{|c|c|c|c|c|c|}
\hline \multirow{2}{*}{ Model } & \multicolumn{2}{|c|}{ Unstandardized } & Standard & \multirow{2}{*}{ T value } & \\
\cline { 2 - 5 } & SE & B & Beta & & \\
\hline (constant) & 1.749 & 68.595 & - & 39.229 & 0.001 \\
Cognitive styles & 0.141 & -.673 & -0.373 & 4.788 & 0.001 \\
resilience & 0.034 & -0.150 & -.0349 & 4.477 & 0.001 \\
\hline
\end{tabular}


As table shows, cognitive styles have a negative effect on students' academic burnout $($ Beta $=0.373, \mathrm{p}<0.01)$, this variable has a special and significant effect on predicting students' academic burnout. After cognitive styles, "resilience" also have a significant effect on students' academic burnout $(\mathrm{p}<0.01)$, this variable also plays a special and significant role in predicting students' academic burnout.

The results of Pearson's coefficient correlation to study the connection between cognitive styles and resilience provided in table4.

Table 4. The results of Pearson's coefficient correlation to study the relationship between cognitive styles and resilience.

\begin{tabular}{|c|c|c|c|c|}
\hline Variable & Mean & Standard Deviation & sig \\
\hline Cognitive styles & 1.39 & 0.95 & \multirow{2}{*}{0.04} & 0.903 \\
\hline Resilience & 14.12 & 5.20 & & \\
\hline
\end{tabular}

One can see in the table that, Pearson coefficient correlation shows a very weak relationship between students' cognitive styles and resilience. It is noticed that significance level is more than 0.05 ( $\mathrm{p}>0.05$ ), therefore, the relationship is not significant.

\section{Discussion}

The aim of this research was to anticipate academic burnout based on cognitive styles and psychological resilience. The results showed that there is a significant difference between students' academic burnout based up cognitive styles and resilience and this finding is consistent with (Salmela-Aro, Savolainen, and Holopainen (2009), (Martínez Martínez, Marques Pinto, Salanova, \& Lopes da Silva (2002), Dobson (2009), Agaibi and Wilson (2005), Bonanno (2004), Paterson and Blume (1996) results.

In explaining this finding, we can take resilience as a sense of self-efficiency; by use of it, we can prevent many serious problems and a trainable and measurable psychological instrument that can possibly be effectively coping in critical conditions and then prevent from Academic burnout. Psychological variables have an important role in educational progress and development, therefore, aims and instructive planning and learning styles must be in a parallel direction with development and worth.

Another important finding is a prediction of academic burnout dimension by Cognitive styles. The results showed that cognitive style have a negative relationship (as much as -0.37) with academic burnout, it is noticeable that this variable has a special and significant role in predicting students' academic burnout, and this finding is consistent with Manta's researches (2010) Salmela-Aro, et al (2008), Robins et al, (2006), Davidson (2000), Gu \& Dey (2007) Agaibi (2005), Banano (2004), Patterson and Blum (1996) results.

Therefore, we can infer that students who are uneager to lessons and education, perhaps they do not try sufficiently and do not try tirelessly in its part will lead to the reduction of academic performance and burnout. Therefore, we can conclude that by applying cognitive learning styles, students' involvement will increase their motivation and interest in lessons and education and applying assignment appropriately to their ability will overcome academic burnout or improve the situation.

Resilience will predict the dimension of students' academic burnout in Hamadan; the results showed that resilience is the second factor affecting the students' academic burnout significantly; the first factor was cognitive styles. By noticing the results, we can infer that certainly this variable also can be a good and significant predictor in determining students' academic burnout, 
an increment of resilience deviation scores by one unit, thus an academic burnout. This finding is consistent with previous studies (Agaibi \& Wilson, 2005; Bonanno, 2004; Davidson, 1977; Patterson \& Blum, 1996; Salmela-Aro et al., 2009).We can explain this finding in such a way that people with high resilience, will not stop attempting, and while facing difficulties in education, they seek appropriate solutions to overcome difficulties. These people with proper planning will cut their stress down to minimum, as durable stress is one of the major cause of educational burnout, while facing academic burnout, such people have the capability to manage the academic requirement and prevent academic burnout, and also we will talk about hypothesis 4 test and see where this hypothesis lead the research:

Of course there is a relationship between cognitive styles and students' resilience in Hamadan; considering the results, we can say that there is a weak relationship between (0.04, $\mathrm{p}>0.05)$ cognitive styles and academic resilience, therefore the relationship is not significant; this finding is incongruent with Zimmerman and Arunkumar (1994) findings.

In general psychological variables have significant and important roles in educational performances and functions. With assessing and evaluating these variables and recognize at risk cases we can prevent academic burn out and safe mental health.

\section{References}

Agaibi, C. E., \& Wilson, J. P. (2005). Trauma, PTSD, and resilience: A review of the literature. Trauma, Violence, \& Abuse, 6(3), 195-216.

Ainley, J., Graetz, B., Long, M., \& Batten, M. (1995). Socioeconomic status and school education. Melbourne: Australian Council for Educational Research.

Bonanno, G. A. (2004). Loss, trauma, and human resilience: have we underestimated the human capacity to thrive after extremely aversive events? American psychologist, 59(1), 20.

Bresó, E., Salanova, M., \& Schaufeli, W. B. (2007). In search of the "third dimension" of burnout: Efficacy or inefficacy? Applied psychology, 56(3), 460-478.

Chambel, M. J., \& Curral, L. (2005). Stress in academic life: work characteristics as predictors of student well-being and performance. Applied psychology, 54(1), 135-147.

Connor, K. M., \& Davidson, J. R. (2003). Development of a new resilience scale: The ConnorDavidson resilience scale (CD-RISC). Depression and anxiety, 18(2), 76-82.

Cordes, C. L., \& Dougherty, T. W. (1993). A review and an integration of research on job burnout. Academy of management review, 18(4), 621-656.

Davidson, D. (1977). The effect of individual differences of cognitive style on judgments of document relevance. Journal of the Association for Information Science and Technology, 28(5), 273-284.

Dobson, J. L. (2009). Learning style preferences and course performance in an undergraduate physiology class. Advances in Physiology Education, 33(4), 308-314.

Draper, M. L., Stutes, D. S., Maples, N. J., \& Velligan, D. I. (2009). Cognitive adaptation training for outpatients with schizophrenia. Journal of clinical psychology, 65(8), 842-853.

Folkman, S., Lazarus, R. S., Gruen, R. J., \& DeLongis, A. (1986). Appraisal, coping, health status, and psychological symptoms. Journal of personality and social psychology, 50(3), 571.

Klohnen, E. C. (1996). Conceptual analysis and measurement of the construct of ego-resiliency. Journal of personality and social psychology, 70(5), 1067.

Lee, R. T., \& Ashforth, B. E. (1996). A meta-analytic examination of the correlates of the three dimensions of job burnout: American Psychological Association. 
Malakh-Pines, A., Aronson, E., \& Kafry, D. (1981). Burnout: From tedium to personal growth: Free Pr.

Martínez Martínez, I., Marques Pinto, A., Salanova, M., \& Lopes da Silva, A. (2002). Burnout en estudiantes universitarios de España y Portugal. Un estudio transcultural. Ansiedad estrés, 13-23.

Maslach, C. (1998). A multidimensional theory of burnout. Theories of organizational stress, 68.

Maslach, C., Jackson, S., \& Leiter, M. (1996). Maslach Burnout Inventory Manual, 3rd edn. Mountain View, CA: CPP: Inc.

Maslach, C., \& Pines, A. (1977). The burn-out syndrome in the day care setting. Child care quarterly, 6(2), 100-113.

Maslach, C., Schaufeli, W. B., \& Leiter, M. P. (2001). Job burnout. Annual review of psychology, 52(1), 397-422.

McCarthy, M. E., Pretty, G. M., \& Catano, V. (1990). Psychological sense of community and student burnout. Journal of college student development.

Meier, S. T., \& Schmeck, R. (1985). The burned-out college student: A descriptive profile. Journal of College Student Personnel.

Patterson, J., \& Blum, R. W. (1996). Risk and resilience among children and youth with disabilities. Archives of pediatrics \& adolescent medicine, 150(7), 692-698.

Ramist, L. (1981). College student attrition and retention.

Richardson, G. E. (2002). The metatheory of resilience and resiliency. Journal of clinical psychology, 58(3), 307-321.

Rutter, M. (2008). Developing concepts in developmental psychopathology. Developmental psychopathology and wellness: Genetic and environmental influences, 3-22.

Salmela-Aro, K., Savolainen, H., \& Holopainen, L. (2009). Depressive symptoms and school burnout during adolescence: Evidence from two cross-lagged longitudinal studies. Journal of Youth and Adolescence, 38(10), 1316-1327.

Sternberg, R. J., \& Grigorenko, E. L. (1997). Are cognitive styles still in style? American psychologist, 52(7), 700.

Tracey, T. J., \& Robbins, S. B. (2006). The interest-major congruence and college success relation: A longitudinal study. Journal of Vocational Behavior, 69(1), 64-89.

Witkin, H. A., Moore, C. A., Oltman, P. K., Goodenough, D. R., Friedman, F., Owen, D. R., \& Raskin, E. (1977). Role of the field-dependent and field-independent cognitive styles in academic evolution: a longitudinal study. Journal of educational psychology, 69(3), 197.

Yang, H.-J. (2004). Factors affecting student burnout and academic achievement in multiple enrollment programs in Taiwan's technical-vocational colleges. International Journal of Educational Development, 24(3), 283-301.

Zimmerman, M., \& Arunkumar, R. (1994). Resiliency research: Implications for schools and policy (Society for Research in Child Development Social Policy Report, VIII, 4). Ann Arbor, MI: Society for Research in Child Development. 